\title{
Characterization of microflora in Latin-style cheeses by next-generation sequencing technology
}

Tina S Lusk** ${ }^{*}$ Andrea R Ottesen ${ }^{2}$, James R White ${ }^{3}$, Marc W Allard², Eric W Brown ${ }^{2}$ and Julie A Kase ${ }^{2}$

\begin{abstract}
Background: Cheese contamination can occur at numerous stages in the manufacturing process including the use of improperly pasteurized or raw milk. Of concern is the potential contamination by Listeria monocytogenes and other pathogenic bacteria that find the high moisture levels and moderate $\mathrm{pH}$ of popular Latin-style cheeses like queso fresco a hospitable environment. In the investigation of a foodborne outbreak, samples typically undergo enrichment in broth for 24 hours followed by selective agar plating to isolate bacterial colonies for confirmatory testing. The broth enrichment step may also enable background microflora to proliferate, which can confound subsequent analysis if not inhibited by effective broth or agar additives. We used 16S rRNA gene sequencing to provide a preliminary survey of bacterial species associated with three brands of Latin-style cheeses after 24-hour broth enrichment.

Results: Brand A showed a greater diversity than the other two cheese brands (Brands B and C) at nearly every taxonomic level except phylum. Brand B showed the least diversity and was dominated by a single bacterial taxon, Exiguobacterium, not previously reported in cheese. This genus was also found in Brand C, although Lactococcus was prominent, an expected finding since this bacteria belongs to the group of lactic acid bacteria (LAB) commonly found in fermented foods.

Conclusions: The contrasting diversity observed in Latin-style cheese was surprising, demonstrating that despite similarity of cheese type, raw materials and cheese making conditions appear to play a critical role in the microflora composition of the final product. The high bacterial diversity associated with Brand A suggests it may have been prepared with raw materials of high bacterial diversity or influenced by the ecology of the processing environment. Additionally, the presence of Exiguobacterium in high proportions (96\%) in Brand B and, to a lesser extent, Brand C (46\%), may have been influenced by the enrichment process. This study is the first to define Latin-style cheese microflora using Next-Generation Sequencing. These valuable preliminary data will direct selective tailoring of agar formulations to improve culture-based detection of pathogens in Latin-style cheese.
\end{abstract}

Keywords: Latin-style cheese, Next Generation Sequencing, Microflora, Bacteria, Exiguobacterium

\section{Background}

Latin-style cheeses continue to be highly popular in the United States, with 215 million pounds produced in 2010, up nearly 4\% from 2009 [1]. Yearly per capita consumption in the United States is 0.65 pounds per person, an increase of $150 \%$ from 1997 to 2008 [2]. According to Dairy Management Inc., a non-profit group funded by

\footnotetext{
* Correspondence: tina.lusk@fda.hhs.gov

'Oak Ridge Institute for Science and Education, Oak Ridge TN 38730,

Tennessee

Full list of author information is available at the end of the article
}

dairy producers that promotes dairy products within the United States, foreign-born Hispanics constitute onehalf of the US cheese consumer [3]. If migration rates remain constant and the population doubles from 2000 levels in 2050 as expected, the consumption of Latinstyle cheese is likely to rise as a result $[3,4]$.

Soft Latin-style cheeses like queso fresco typically are not aged, have a short shelf-life (about 2 weeks), and have a high moisture content (41/59\%) [5]. The lack of an aging step as well as high moisture content and the moderate $\mathrm{pH}$ level of Latin-style cheeses can all

\section{Biomed Central}


contribute to pathogen growth and increases the likelihood of pathogens surviving and possibly multiplying to the levels necessary to cause illness [6]. For this reason, the US FDA prohibits the interstate sale of this cheese type if it is manufactured using raw milk [5]. However, for some the taste of Latin-style cheese made with raw milk is preferable.

Between 1998 and 2009, 56 cheese-associated disease outbreaks occurred in the United States resulting in 1,377 illnesses, 171 hospitalizations, and 2 deaths [7-9]. Eighteen of these occurrences (32\%) specifically involved Latin-style cheeses and a variety of pathogens, resulting in 212 illnesses (15\% of total), 95 hospitalizations (55\%), 2 deaths (100\%), and at least 7 stillbirths [10]. Individuals making homemade cheese (i.e. bathtub cheese) sold in grocery stores accounted for 85 illnesses [7-9,11]. The most serious outbreak involving Latin-style cheeses occurred in 1985; 142 cases of listeriosis caused 48 deaths, of which 30 involved neonates or fetuses [10].

In response to a foodborne outbreak, suspect samples are analyzed according to standardized methods including those described in the FDA Bacteriological Analytical Manual (BAM). One goal of analysis is to recover isolated colonies of the pathogenic bacteria that can assist in matching any recovered clinical, food, and environmental isolates to determine the source(s) of illness. Most methods described in the FDA BAM begin with enriching the suspected food product in a universal or microbe-specific enrichment broth for up to 24 hours. The sample is then plated onto selective agar specific for the target bacteria to obtain isolated colonies. The initial enrichment step is designed to recover and propagate bacterial pathogens in the product facilitating downstream detection efforts. However, enrichment can also influence levels of background microflora. A food sample may consist of a complex consortium of bacteria that can out-compete and otherwise hinder efforts to recover human pathogens. With improved characterization of the microbial taxonomy and abundance associated with a given enriched food product, broths and agar formulations can be vastly improved in terms of culture selectivity.

Several studies have attempted to describe the full range of microbes present in cheeses as well as in various steps along the manufacturing and maturation process to understand temporal microflora changes [12-18]. The most widely-used approach begins with the plating of cheese samples on agar and picking isolated colonies for subsequent identification using biochemical analyses or molecular characterization. These methods are labor intensive and inherently biased $[19,20]$. For this reason, culture-independent techniques, including single stranded confirmation polymorphisms (SSCP) analysis of DNA and restriction fragment length polymorphism
(RFLP) typing of isolates, have been used increasingly to study the bacterial populations in milk and/or cheese [20]. Next Generation Sequencing (NGS) techniques are extremely useful because of the enhanced sequencing depth that can be achieved compared to previous technologies for relatively low cost without the bias introduced by culture techniques. To date, NGS methods have been applied most prolifically to describe the human microbiome [21], but they have also been widely used to describe a vast array of environmental and agricultural ecologies, including microflora of trees [22] and tomato surfaces [23], and even for epidemiological approaches in hospital pathogen tracking [24]. This technology has also been used to study the bacterial diversity of other cheeses as well, including artisanal cheeses [25], traditional Polish cheeses [26], and Danish semi-hard cheese [27]. However, the application of NGS methods to evaluate food microbiomes is still in its infancy.

\section{Results}

We recovered 3708 high-quality 16 SrRNA gene sequences with an average sequence length of $370 \mathrm{bp}$ and $309 \pm 92.6$ (SD) sequences per enriched cheese sample. From the four replicate Brand C cheese samples, a total of $1284 \pm 92.8$ sequences were recovered, $1187 \pm 137.55$ sequences were recovered from Brand A cheese, and Brand B produced $1237 \pm 59.1$ sequences. To compare environments for differentially-abundant taxonomic groups at the 0.05 significance level, Metastats (a program designed to identify significant taxonomic differences between microbial communities) [28] was used for phylum, class, order, family and genus level assignments. Average abundance of bacterial classifications are presented in Table 1 along with p-values of brand comparisons.

\section{Taxonomic distributions among samples}

After assigning sequences to a taxonomic lineage using the RDP Bayesian classifier, we first examined the phylum level distributions across all enriched cheese samples and found fairly similar $16 \mathrm{~S}$ rRNA profiles between all three cheese brands (Table 1). Firmicutes dominated the observed sequences in all cheese samples, with the highest proportions found in all four Brand B samples (100\%), the next highest in Brand C (71-88\%), and the lowest in Brand A (56-82\%). Brand A and Brand C samples were more diverse at the phylum level than Brand B, with Proteobacteria constituting 12-29\% of sequences from Brand $C$ samples and 18-43\% of Brand A samples.

Differences between the cheeses become more evident at class level classification. Brand A samples have a significantly different profile than the other two cheese brands. Class-level abundance profiles for Brand $\mathrm{C}$ and 
Table 1 Average abundance (\%) of sequences assigned to taxa in all cheese brands

\begin{tabular}{|c|c|c|c|c|c|}
\hline & Classification & Brand A (\%) & Brand B (\%) & Brand C (\%) & Significant Difference? $(p \leq 0.05)$ \\
\hline \multirow[t]{6}{*}{ Phylum } & Firmicutes & 68 & 100 & 81 & $(A$ and $B, p=0.006)$ \\
\hline & & & & & $A$ and $C, p=0.135$ \\
\hline & & & & & $B$ and $C, p=0.0)$ \\
\hline & Proteobacteria & 29 & 0 & 19 & $(A$ and $C, p=0.141$ \\
\hline & & & & & $A$ and $B, p=0.0$ \\
\hline & & & & & $B$ and $C, p=0.012$ ) \\
\hline \multirow[t]{8}{*}{ Class } & Clostridia & 66 & 0 & 0 & (A and $C, p=0.004$ \\
\hline & & & & & $A$ and $B, p=0.01$ ) \\
\hline & Gammaproteobacteria & 22 & 0 & 19 & (A and $C, p=0.65$ \\
\hline & & & & & $A$ and $B, p=0.005$ \\
\hline & & & & & $B$ and $C, p=0.0)$ \\
\hline & Bacilli & 2 & 100 & 81 & ( $A$ and $B, p=0.0$; \\
\hline & & & & & $A$ and $C, p=0.0$ \\
\hline & & & & & $B$ and $C, p=0.011)$ \\
\hline \multirow[t]{13}{*}{ Order } & Clostridiales & 67 & 0 & 0 & $(A$ and $C, p=0.003$ \\
\hline & & & & & $A$ and $B, p=0.004)$ \\
\hline & Lactobacillales & 0 & 0 & 22 & $(A$ and $C, p=0.005$ \\
\hline & & & & & $C$ and $B, p=0.006)$ \\
\hline & Enterobacteriales & 9 & 0 & 14 & (A and $C, p=0.03$ \\
\hline & & & & & $A$ and $B, p=0.002$ \\
\hline & & & & & $B$ and $C, p=0.012)$ \\
\hline & Pseudomonadales & 9 & 0 & 5 & $(A$ and $C, p=0.049$ \\
\hline & & & & & $A$ and $B, p=0.049$ \\
\hline & & & & & $B$ and $C, p=0.017)$ \\
\hline & Bacillales & 2 & 100 & 59 & ( $A$ and $B, p=0.0$; \\
\hline & & & & & $A$ and $C, p=0.0$ \\
\hline & & & & & $B$ and $C, p=0.0)$ \\
\hline \multirow[t]{17}{*}{ Family } & Incertae Sedis XII & 0 & 96 & 45 & (A and $B, p=0.0$; \\
\hline & & & & & $A$ and $C, p=0.0$ \\
\hline & & & & & $B$ and $C, p=0.0)$ \\
\hline & Staphylococcaceae & 0 & 3 & 0 & $(A$ and $B, p=0.01$ \\
\hline & & & & & $\mathrm{B}$ and $\mathrm{C}, \mathrm{p}=0.01$ ) \\
\hline & Planococcaceae & 0 & 0 & 14 & (A and $C, p=0.002$ \\
\hline & & & & & $B$ and $C, p=0.004)$ \\
\hline & Streptococcaceae & 0 & 0 & 22 & $(A$ and $C, p=0.005$ \\
\hline & & & & & $B$ and $C, p=0.007)$ \\
\hline & Clostridiaceae & 67 & 0 & 0 & $(A$ and $B, p=0.007$ \\
\hline & & & & & $A$ and $C, p=0.004)$ \\
\hline & Enterobacteriaceae & 9 & 0 & 14 & $(A$ and $B, p=0.002$ \\
\hline & & & & & $A$ and $C, p=0.025$ \\
\hline & & & & & $B$ and $C, p=0.01$ ) \\
\hline & Pseudomonadaceae & 7 & 0 & 5 & $(A$ and $B, p=0.008$ \\
\hline & & & & & $A$ and $C, p=0.12$ \\
\hline & & & & & $B$ and $C, p=0.04)$ \\
\hline
\end{tabular}


Table 1 Average abundance (\%) of sequences assigned to taxa in all cheese brands (Continued)

\begin{tabular}{|c|c|c|c|c|c|}
\hline \multirow[t]{20}{*}{ Genus } & \multirow[t]{3}{*}{ Exiguobacterium } & \multirow[t]{3}{*}{0} & \multirow[t]{3}{*}{96} & \multirow[t]{3}{*}{45} & (A and $B, p=0.0$ \\
\hline & & & & & $A$ and $C, P=0.0$ \\
\hline & & & & & $B$ and $C, p=0.0)$ \\
\hline & \multirow[t]{2}{*}{ Kurthia } & \multirow[t]{2}{*}{0} & \multirow[t]{2}{*}{0} & \multirow[t]{2}{*}{14} & $(\mathrm{~A}$ and $\mathrm{C}, \mathrm{P}=0.001$ \\
\hline & & & & & $B$ and $C, p=0.003$ ) \\
\hline & \multirow[t]{2}{*}{ Clostridiaceae } & \multirow[t]{2}{*}{68} & \multirow[t]{2}{*}{0} & \multirow[t]{2}{*}{0} & (A and $B, p=0.006$ \\
\hline & & & & & $A$ and $C, p=0.002$ ) \\
\hline & \multirow[t]{3}{*}{ Raoultella } & \multirow[t]{3}{*}{7} & \multirow[t]{3}{*}{0} & \multirow[t]{3}{*}{10} & $(A$ and $B, p=0.002$ \\
\hline & & & & & $\mathrm{A}$ and $\mathrm{C}, \mathrm{P}=0.18$ \\
\hline & & & & & $B$ and $C, p=0.012$ ) \\
\hline & \multirow[t]{3}{*}{ Pseudomonas } & \multirow[t]{3}{*}{7} & \multirow[t]{3}{*}{0} & \multirow[t]{3}{*}{5} & $(A$ and $B, p=0.008$ \\
\hline & & & & & $A$ and $C, p=0.16$ \\
\hline & & & & & $B$ and $C, p=0.034$ ) \\
\hline & \multirow[t]{3}{*}{ Lactococcus } & \multirow[t]{3}{*}{2} & \multirow[t]{3}{*}{0} & \multirow[t]{3}{*}{22} & ( $A$ and $B, p=0.006$ \\
\hline & & & & & A and $C, p=0.004$ \\
\hline & & & & & $B$ and $C, p=0.006)$ \\
\hline & \multirow[t]{2}{*}{ Staphylococcus } & \multirow[t]{2}{*}{0} & \multirow[t]{2}{*}{3} & \multirow[t]{2}{*}{0} & $(A$ and $B, p=0.01$ \\
\hline & & & & & $\mathrm{B}$ and $\mathrm{C}, \mathrm{p}=0.009$ ) \\
\hline & \multirow[t]{2}{*}{ Enterobacteriaceae_Other } & \multirow[t]{2}{*}{0} & \multirow[t]{2}{*}{0} & \multirow[t]{2}{*}{2} & (A and $C, p=0.008$ \\
\hline & & & & & $B$ and $C, p=0.018$ ) \\
\hline
\end{tabular}

Taxa represented occurred at $\geq 1 \%$ abundance of the total for each brand.

Brand B samples are clearly dominated by Bacilli taxa, while Brand A appears to be dominated by Clostridia (49-82\%). Gammaproteobacteria comprise the majority of the remaining diversity for Brands $\mathrm{A}$ and $\mathrm{C}$ with 17$26 \%$, and $12-29 \%$, respectively.

Similarities are shared by Brand B and Brand C at the genus level (Table 1). Both are dominated by Exiguobacterium, though it constitutes nearly all Brand B abundance at $96 \%$ while it shows lower abundance in Brand $\mathrm{C}$ at $45 \%$. Not surprisingly, Brand $\mathrm{C}$ shows much more diversity than Brand $\mathrm{B}$ at the genus level, with 6 operational taxonomic units (OTU) compared to only 2 identified in Brand B. Unlike the other brands, Brand A is dominated by Clostridiaceae (68\%) at the genus level. Brands A and C share 3 OTUs - Raoultella, Pseudomonas, and Lactococcus. However, only Lactococcus was significantly more abundant ( $\mathrm{p}$-value $=0.004$ ) between the brands, with Brand $C$ consisting of $22 \%$ of this classification versus $2 \%$ of Brand $B$.

Within each cheese brand, abundance percentages for dominant OTUs in the genus classification are similar to those at the order and family classifications from which they descended. For instance, Brand B is comprised of the family Incertae Sedis XII (96\%) within the order Bacillales (100\%), which is not surprising since this brand is almost entirely dominated by a single classification (Exiguobacterium) at the genus level that falls within the family Incertae Sedis XII. Similar to Brand B, Brand C is also dominated by Incertae Sedix XII (45\%) and Bacillales (59\%), as well as Exiguobacterium (46\%) at the genus level. Brand $\mathrm{A}$ is dominated by Clostridiaceae $(67 \%)$ at the family level, which falls within the order Clostridiales noted in Brand A at 67\% abundance. Clostridiaceae dominates Brand $\mathrm{A}$ at the genus level with $68 \%$, which falls within the Clostridiaceae family.

The diversity and uniqueness of Brand A cheese is partially explained by a replicate within Brand A, replicate Brand A_rep1, that appears to have more diversity at the class level than the other 3 replicates, with the presence of Alphaproteobacteria, Actinobacteria, and Betaproteobacteria, of which only Alphaproteobacteria is shared by Brand A_rep3 in very low abundance. This diversity is evident at the genus level as well (Figures 1 and 2), with Brand A_rep1 containing 4 operational taxonomic units (OTUs) not found in any other Brand A replicates, nor in any samples from the other cheese brands, using a 95\% identity threshold for clustering sequences. In addition, Brand A_rep1 contains 13 OTUs total that occurred at $\mathrm{a} \geq 1 \%$ abundance in the sample at the genus level, while the other Brand A replicates as well as all replicates from the other cheese brands contain no more than 7 OTUs per sample.

\section{Diversity analysis using operational taxonomic units}

Rarefaction curves of all enriched cheese samples (Figure 3), also support the observation that Brand A samples supported the greatest diversity among the three cheeses. The greater diversity of Brand A cheese 


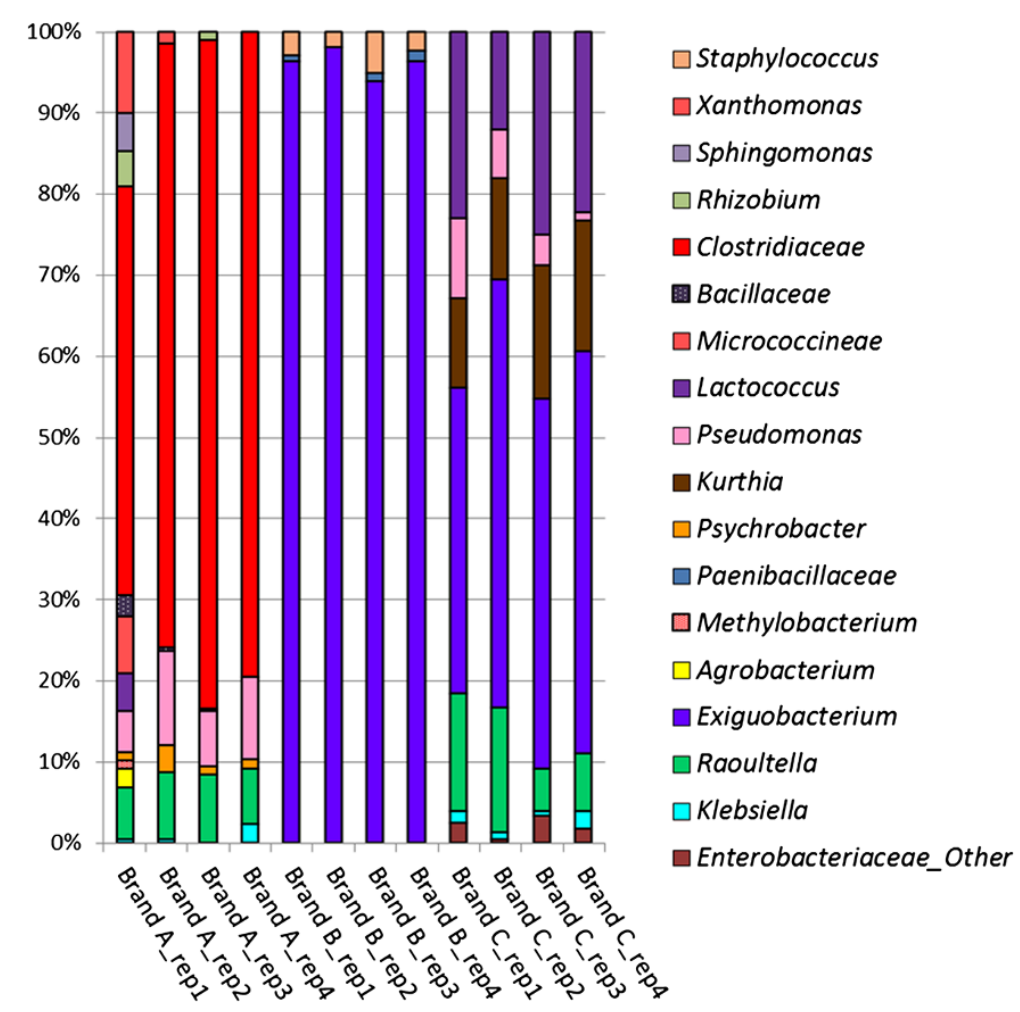

Figure 1 Genus level abundance profiles using 16S rRNA sequence classifications. Taxa represented occurred at $\geq 1 \%$ abundance in that sample.

sample Brand A_rep1 is displayed, rising dramatically above all other samples. This is confirmed with the UniFrac metric, which shows the replicate samples of each brand distinctly clustered together by brand except for Brand A_rep1. Brand C replicates cluster together rather tightly, more so than the Brand $\mathrm{B}$ replicates.

\section{CloVR analysis}

Using the automated $16 \mathrm{~S}$ rRNA pipelines provided by the CloVR software package (http://clovr.org). Replicates within each cheese type clustered as expected at the genus level except for the Brand A_ rep1 (Figure 2). Brand $\mathrm{B}$ samples show the least diversity of the cheese brands with only 2 genera identified in substantial quantities (Exiguobacterium and Staphylococcus). Brand C shows a bit more diversity, dominated clearly by Exiguobacterium though other genus are present including Raoultella, Pseudomonas, Lactococcus, Kurthia, and other Enterobacteriaceae. Brand A shares Raoultella and Pseudomonas with Brand $\mathrm{C}$ and low amounts of Klebsiella, but it is still dominated by Clostridiaceae with trace amounts of a variety of genera. Brand A_rep1 shows more diversity than all the other Brand A replicates, as well as, all the other cheese brand replicates.

\section{Discussion}

This study provides the first Next-Generation Sequencing (NGS) survey of the bacterial community in Latinstyle cheeses. The order Lactobacillales was present in significant abundance in all Brand $\mathrm{C}$ replicates, which is expected since lactic acid bacteria are known for their role in the production of fermented foods including cheese (Table 1). Renye et al. sampled queso fresco from Mexico, plated samples on selective agar, and subjected colonies to 16S rRNA sequencing [29]. Lactococcus lactis, of the order Lactobacillales, was found in the highest numbers in both the cheeses made with raw milk and those made with pasteurized milk. Leuconostoc mesenteroides, another member of the Lactobacillales order, was also abundant [29].

The genus Exiguobacterium of the order Bacillales dominated all Brand B samples in this study; however, this genus has not been previously reported in cheese [29]. Food matrices in which this genus has been identified include raw milk [30,31], however, as well as potato processing effluent and water-boiled salted duck $[32,33]$. Exiguobacterium have been identified in a wide variety of non-food matrices including surface and pond water, oral cancer tumors, hot springs in Yellowstone National Park, Siberian permafrost, coastal soil, and a saline 


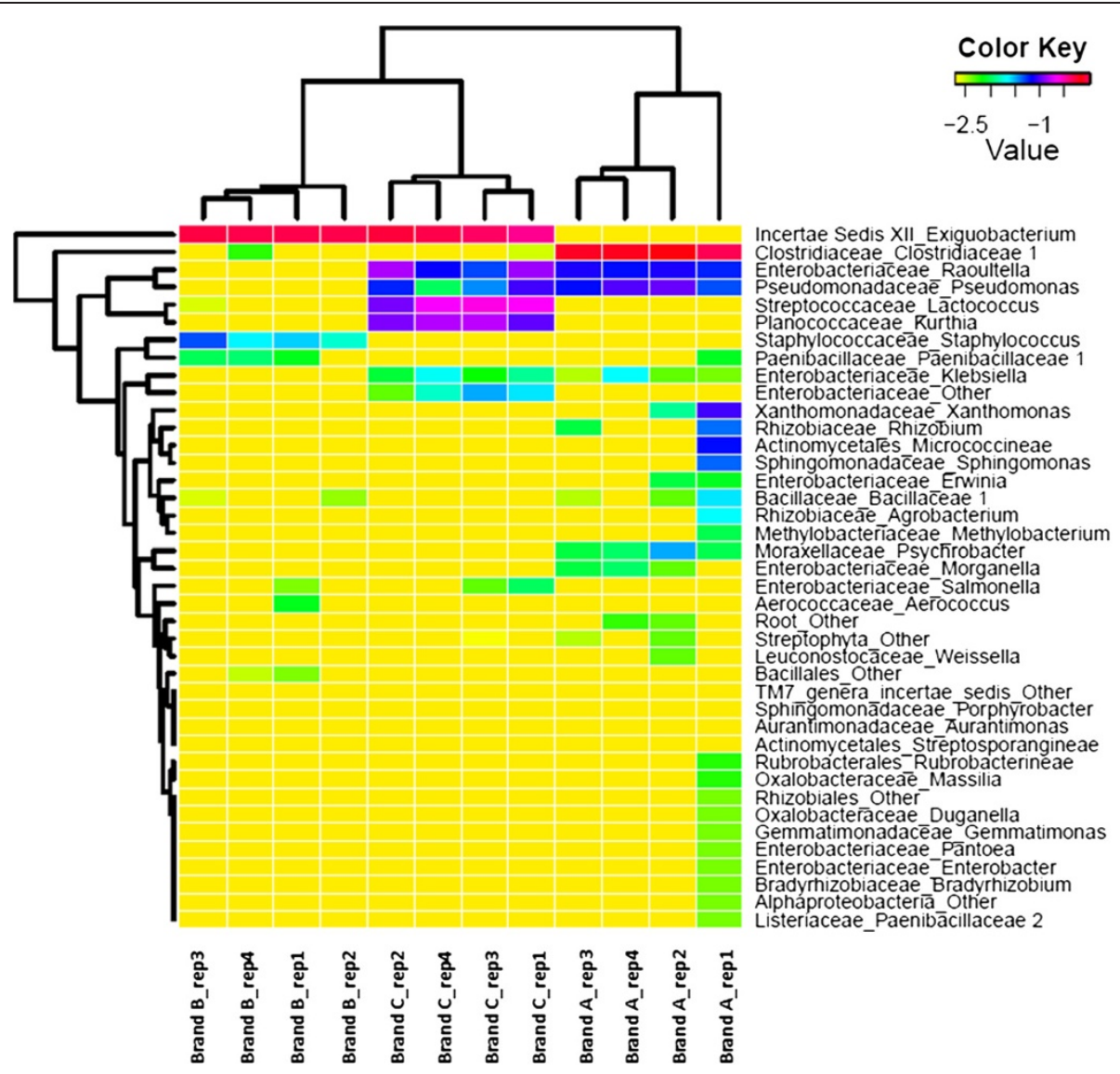

Figure 2 Hierarchical clustering of samples using Genus level distributions. Displayed values are log transformed relative abundances within each sample, (e.g. $0.10 \sim-1 ; 0.01 \sim-2$ ). Visualized using skiff in CloVR.

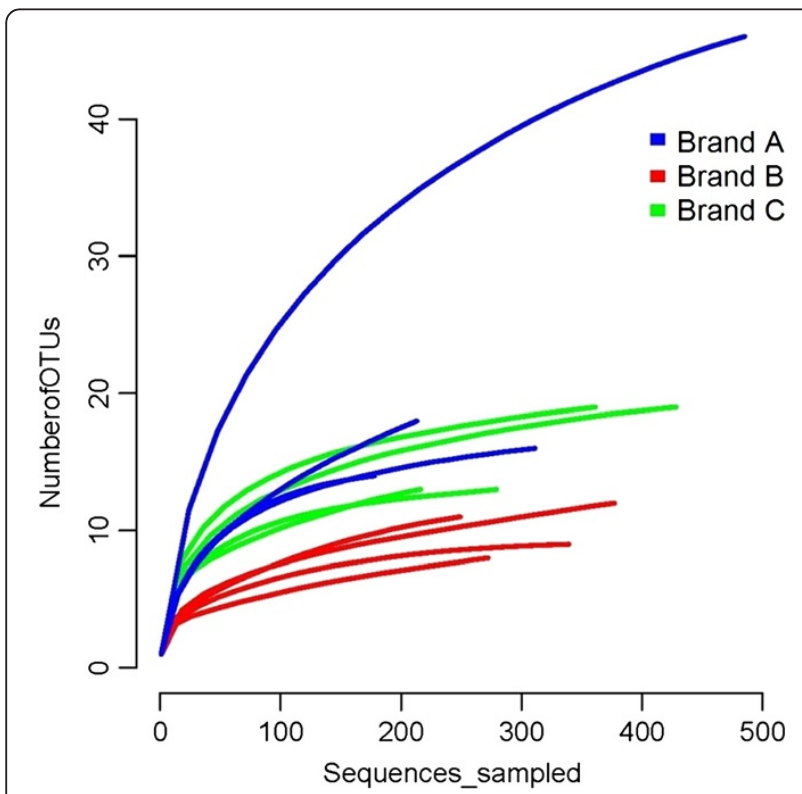

Figure 3 Rarefaction curves of OTUs in all 4 replicates of each cheese brand.
Romanian lake [34-39]. They have also been found to be useful in bioremediation efforts [40].

Serum dextrose broth (SDB) was used in this study due to ongoing research efforts in our laboratory to enrich Brucella species that might be associated with this type of soft cheese. However, SDB is not particularly selective and this rich nutrient source may have allowed uncommon bacteria to out-compete other components of the original metagenomic microflora. The Jameson Effect describes the phenomenon of low abundance microbial species ceasing growth in response to a dominant population's arrival at stationary phase [41-44]. Tran et al. explored microflora and pathogen dynamics by using selective broth and agar to isolate Listeria from inoculated cheese. They found that ease of isolation was not correlated with concentration of inocula, which supports the theory that microbial community composition may play a bigger role in Listeria inhibition than initial concentrations [43]. Due to this potential effect of broth enrichment on the sample microflora, the selective agar employed in the next step in detection is all the more crucial and must be 
formulated taking into account the sample microflora after enrichment.

In this study, all replicates within each cheese brand clustered well, with the exception of Brand A_rep1 in Brand A. Perhaps bacterial DNA extraction was more efficient with this sample; however, there is not a clear reason for this discrepancy since all samples were processed identically and at the same time. Insufficient homogenization is also a possibility since enriched samples were not treated to stomaching between enrichment and aliquot collection. But if this were the case, it's curious that other samples were not similarly affected.

While the three cheese brands used in this study were similar in style, color and texture, the bacterial abundance profiles of each were very different. The cheese manufacturers were contacted for information regarding manufacturing process to elucidate possible reasons for the observed differences (Table 2). In the U.S., commercially available queso fresco is generally prepared with starter cultures; however, this may not be true for queso fresco made in other countries [5,29]. Starter cultures are used in the manufacturing process for Brands $\mathrm{A}$ and $\mathrm{B}$ cheeses (use of starter culture to manufacture Brand $\mathrm{C}$ cheese could not be determined), although information about the specific cultures used could not be obtained. Other information obtained from Brands $\mathrm{A}$ and $\mathrm{B}$ included $\mathrm{pH}, \%$ moisture, salt concentration, and \% fat, but substantial differences were not noted between the two brands (Table 2). Salt concentration was not available for Brand $\mathrm{C}$ cheese. Brand $\mathrm{C}$ does have the lowest $\mathrm{pH}(5.3$ versus 6.2 - 6.7), however this alone may not account for the difference in microflora profiles between Brand $C$ and the other brands. Further study would be required to discern the effect of these and similar parameters on the microflora of the cheese brands.

The methods used in this study do not discern between live and dead cells because the amplification target, 16S ribosomal RNA-encoding genes, is highly conserved in bacteria regardless of viability. Efforts exist to manipulate sample preparation to detect only cells with intact membranes by sample treatment with propidium monoazide in combination with PCR amplification

Table 2 Manufacturer-provided parameters of Brands A, $B$, and $C$ cheeses

\begin{tabular}{llll}
\hline Parameter & Brand A & Brand B & Brand C \\
\hline $\mathrm{pH}$ & 6.5 & $6.2-6.7$ & 5.3 \\
\hline \% moisture & $53-57 \%$ & $49-52 \%$ & $54.53 \%$ \\
\hline Salt concentration & 1.8 & $1.5-2.25$ & $\mathrm{ND}$ \\
\hline$\%$ fat & $22 \%$ & $22-24.5 \%$ & $21.5 \%$ \\
\hline Starter used in manufacture process? & Yes & Yes & $\mathrm{ND}$ \\
\hline
\end{tabular}

$\mathrm{ND}=$ Not Determined.
[45] or the generation of transcriptomes. This will improve NGS as a tool for assessing microflora of cheese at different stages of the aging process. Additionally, Renye et al. found more variety in the types of bacteria isolated from cheeses made with raw milk versus those made with pasteurized milk [29]; another public health risk best evaluated with tools that can distinguish between live and dead cells.

It is known that DNA extraction efficiency varies within and between laboratories, and that this can have an effect on subsequent microflora analysis [46]. We addressed this in a variety of ways. First, the extraction kit used to perform the DNA extractions was chosen based on data collected in which the Qiagen DNeasy Blood and Tissue kit was compared to five other commercially-available kits for the extraction of Brucella neotomae DNA from the same Latin-style cheeses used in this study (T. Lusk, E. Strain, and J.A. Kase, submitted for publication). The Qiagen DNeasy kit was found to produce the highest quality and quantity DNA from this matrix. All extractions were performed by a single person at one time. Lastly, four subsamples of each enriched cheese brand were extracted and sequenced, with all replicates producing similar bacterial profiles within each brand except for Brand A, in which 1 replicate showed more diversity than its counterparts.

\section{Conclusions}

This research presents a first look at the microflora of Latin-style cheese using Next-Generation Sequencing. Our findings offer surprising insight into cheese microflora composition, with three cheese brands exhibiting unique bacterial profiles which varied in diversity and abundance of taxa. Although the cheese are visually similar (e.g. white color and soft, crumbly texture), their bacterial profiles were very different at nearly every classification level. Brand A cheese was clearly more diverse than the other two cheese brands with 13 OTUs at the genus level using a $95 \%$ identity threshold compared to 7 and 3 for Brand C and Brand B, respectively. Additionally, Brand $\mathrm{A}$ was dominated by different genus than Brands B and C. Brand B showed less diversity, mostly dominated at the genus level by Exiguobacterium which constituted $96 \%$ of its microflora composition. Exiguobacterium also made up $46 \%$ of Brand C's profile, although its presence in cheese has not been previously documented though it has been found in milk. Factors such as milk, pH, starter culture, and salt concentration may have contributed to the unique bacterial composition of each cheese brand, although no particular factor was determined to be responsible for differences in abundance between the brands based on the limited available information. Overnight enrichment in a nonselective broth also may have allowed some fast-growing 
bacteria to out-compete and inhibit slower growing bacteria. This emphasizes the importance of examining food samples after the broth enrichment step to provide a more accurate depiction of microflora composition when trying to selectively cultivate target organisms while decreasing competing background flora. More effort is needed to fully characterize cheese microbial populations and to understand the effects of enrichment formulations on population composition. This valuable preliminary data will certainly inform future culturebased efforts.

\section{Methods}

\section{Sample processing}

Three cheeses of different brands were included in the study: Brand A - queso fresco Salvadoreno; Brand C queso fresco; and Brand B - quesito Colombiano. All were Latin-style soft cheeses made with pasteurized milk and were purchased from grocery stores in the Washington, DC area.

Twenty-five gram portions of each cheese type was added to a sterile whirl-pak bag using a sterile spatula and were held overnight at $4^{\circ} \mathrm{C}$, then combined with 250 $\mathrm{mL}$ serum dextrose broth followed by mixing via a Stomacher 400 circulator (Seward, Worthing, West Sussex, UK) for two minutes at 230rpm. The bags were then incubated at $37^{\circ} \mathrm{C}$ overnight. Sample volumes of $1.5 \mathrm{~mL}$ were then collected from each of the 3 cheese brands, four subsamples for each brand, for nucleic acid extraction using the Qiagen DNeasy Blood and Tissue Kit (Qiagen, Valencia, CA). DNA extractions were performed within 24 hours of each other by the same person. All cheeses, if not tested upon receipt, were stored at $4^{\circ} \mathrm{C}$ until use. All cheeses were discarded one month after purchase or by the expiration date printed on the package, if available.

\section{4 sequencing}

PCR amplification for the 16S rRNA bacterial gene (V1V3) was performed using a series of forward primers and one reverse primer described in Table 3. Standard PCRs were performed using Taqman Universal PCR Master Mix (Invitrogen, Carlsbad, CA) in a $50 \mu \mathrm{L}$ total volume $(8 \mu \mathrm{L}$ genomic DNA as template, $800 \mathrm{nM}$ each primer, $25 \mu \mathrm{L}$ Taqman, and $15.2 \mu \mathrm{L}$ reagent grade water). PCRs used an initial denaturation step of $95^{\circ} \mathrm{C}$ for 300 seconds, followed by 29 cycles of $95^{\circ} \mathrm{C}$ for 60 seconds, $55^{\circ} \mathrm{C}$ for 60 seconds, and $72^{\circ} \mathrm{C}$ for 60 seconds, with a final extension of $72^{\circ} \mathrm{C}$ for 300 seconds. After gel-based confirmation of PCR amplification, PCR products were purified using AMPure kit (Invitrogen) to remove primers and sequences under 300 bases. Amplicons were quantified using both the Qubit fluorometer (Invitrogen/ Life Technologies, Grand Island, NY) and the NanoDrop 1000 (ThermoScientific, Waltham, MA). Amplicons were analyzed on the Agilent Bioanalyzer 2100 using the High Sensitivity Lab on a Chip Reagents (Agilent, Santa Clara, CA) to ensure that smaller fragments had been removed prior to emulsion PCR preparation.

\section{Emulsion PCR and sequencing}

Amplicons were diluted to $10^{7}$ molecules per $\mu \mathrm{L}$ and pooled to generate a mixture containing an equimolar representation of each independent replicate for subsequent emulsion PCR. Pooled amplicons were further diluted to estimate 0.5 copies per bead to provide optimal emulsion PCR amplification. Emulsion PCR was done using the Roche Lib-A MV kit according to the manufacturer's specifications.

Approximately 700,000 enriched beads were loaded into one-quarter region of the Roche Titanium FLX pico-titer plate for sequencing on the Titanium FLX platform according to the manufacturer's specifications (Roche, Branford, CT).

Table 3 Forward and reverse primers used to amplify the 16S rRNA bacterial gene of all cheese samples

\begin{tabular}{|c|c|c|}
\hline MID 11 & Brand A_rep1 & CGT ATC GCC TCC CTC GCG CCA TCA GTG ATA CGT CTA GAG TIT GAT CCT GGC TCA G \\
\hline MID 13 & Brand A_rep2 & CGT ATC GCC TCC CTC GCG CCA TCA GCA TAG TAG TGA GAG TIT GAT CCT GGC TCA G \\
\hline MID 14 & Brand A_rep3 & CGT ATC GCC TCC CTC GCG CCA TCA GCG AGA GAT ACA GAG TाT GAT CCT GGC TCA G \\
\hline MID 15 & Brand C_rep1 & CGT ATC GCC TCC CTC GCG CCA TCA GAT ACG ACG TAA GAG TTT GAT CCT GGC TCA G \\
\hline MID 16 & Brand C_rep2 & CGT ATC GCC TCC CTC GCG CCA TCA GTC ACG TAC TAA GAG TाT GAT CCT GGC TCA G \\
\hline MID 17 & Brand C_rep3 & CGT ATC GCC TCC CTC GCG CCA TCA GCG TCT AGT ACA GAG TTT GAT CCT GGC TCA G \\
\hline MID 18 & Brand C_rep4 & CGT ATC GCC TCC CTC GCG CCA TCA GTC TAC GTA GCA GAG TTT GAT CCT GGC TCA G \\
\hline MID 19 & Brand B_rep1 & CGT ATC GCC TCC CTC GCG CCA TCA GTG TAC TAC TCA GAG TIT GAT CCT GGC TCA G \\
\hline MID 20 & Brand B_rep2 & CGT ATC GCC TCC CTC GCG CCA TCA GAC GAC TAC AGA GAG TIT GAT CCT GGC TCA G \\
\hline MID 21 & Brand B_rep3 & CGT ATC GCC TCC CTC GCG CCA TCA GCG TAG ACT AGA GAG TाT GAT CCT GGC TCA G \\
\hline MID 23 & Brand B_rep4 & CGT ATC GCC TCC CTC GCG CCA TCA GTA CTC TCG TGA GAG TIT GAT CCT GGC TCA G \\
\hline MID 24 & Brand A_rep4 & CGT ATC GCC TCC CTC GCG CCA TCA GTA GAG ACG AGA GAG TIT GAT CCT GGC TCA G \\
\hline REV & & CTA TGC GCC TTG CCA GCC CGC TCA GTT ACC GCG GCT GCT GGC AC \\
\hline
\end{tabular}




\section{Initial sequence preprocessing}

Raw 16S rRNA sequences and quality scores were demultiplexed using standard sff processing software with adapted scripts to address additional MIDS. Sequences and quality scores were then submitted to the CloVR-16S [47] pipeline for quality screening and analysis. CloVR includes a variety of widely used $16 \mathrm{~S}$ analysis software including QIIME [48] and Mothur [49]. Only sequences $\geq 200$ nucleotides in length were included in the final analysis. Sequences containing homopolymers of more than $8 \mathrm{bp}$, or average quality scores lower than 25, or ambiguous base calls were culled from the analysis. Remaining sequences were screened for chimeras using UCHIME [50] with the default parameters. The resulting chimera-free high-quality data set was analyzed by clustering sequences into operational taxonomic units at 95\% identity using UCLUST, assigning taxonomy using the RDP classifier [51] (with a minimum confidence threshold of 50\%) and performing additional statistical analyses with Metastats [28] and $\mathrm{R}$ scripts. A detailed description of the available SOP is available at (http://clovr.org) [52].

\section{Authors' contributions}

$J K, A O$, and $T L$ conceived the study and participated in its design. $A O$ and $T L$ performed all lab work. JW performed data analysis. TL drafted the manuscript. $\mathrm{AO}, \mathrm{JW}, \mathrm{JK}, \mathrm{MA}$, and $\mathrm{EB}$ contributed to the draft of the manuscript. All authors read and approved the final manuscript.

\section{Acknowledgements}

This project was supported in part by an appointment (TSL) to the Research Participation Program at the Center for Food Safety and Applied Nutrition administered by the Oak Ridge Institute for Science and Education through an interagency agreement between the U.S. Department of Energy and the U.S. Food and Drug Administration.

\section{Author details}

'Oak Ridge Institute for Science and Education, Oak Ridge TN 38730, Tennessee. ${ }^{2}$ Division of Microbiology, Center for Food Safety and Applied Nutrition, US Food and Drug Administration, 5100 Paint Branch Parkway, College Park MD 20740, MD, USA. ${ }^{3}$ Institute for Genome Sciences, University of Maryland School of Medicine, 801 W. Baltimore St., Baltimore MD 21201, MD, USA.

Received: 29 May 2012 Accepted: 24 October 2012

Published: 7 November 2012

\section{References}

1. USDA: Dairy Products 2010 Summary. http://usda01.library.cornell.edu/usda/ nass/DairProdSu//2010s/2011/DairProdSu-04-27-2011.pdf.

2. Gould B: Understanding Dairy Markets - Per Capita Hispanic Cheese Consumption. http://future.aae.wisc.edu/data/annual_values/by_area/2196? tab=sales.

3. Dairy Management Inc: Understanding the Dairy Opportunity Among Hispanic Consumers. http://www.dairyfoods.com/ext/resources/Digital_Brochures/DFHispanic-White-Paper-FINAL.pdf.

4. Ortman JM, Guarneri CE: United States Population Projections: 2000 to 2050. http://www.census.gov/population/www/projections/analyticaldocument09.pdf.

5. Clark S, Costello M, Drake M, Bodyfelt F: Chapter 16 Latin American Cheeses. In Sensory Evaluation of Dairy Products. 2nd edition. Edited by Clark S, Costello M, Drake M, Bodyfelt F. New York: Springer - Verlag; 2009:493-494.
6. Genigeorgis C, Carniciu M, Dutulescu D, Farver TB: Growth and survival of Listeria monocytogenes in market cheeses stored at 4 to 30 degrees $C$. J Food Prot 2012, 54:662-668.

7. Centers for Disease Control and Prevention: Food Outbreak Online Database. http://wwwn.cdc.gov/foodborneoutbreaks.

8. Centers for Disease Control and Prevention: Outbreak of MultidrugResistant Salmonella enterica serotype Newport Infections Associated with Consumption of Unpasteurized Mexican-Style Aged Cheese. MMWR 2008, 57(16):432-435.

9. Jackson K, Biggerstaff M, Tobin-D'Angelo M, Sweat D, Klos R, Nosari J, Garrison O, Boothe E, Saathoff-Huber L, Hainstock L: Multistate outbreak of Listeria monocytogenes associated with Mexican-style cheese made from pasteurized milk among pregnant, Hispanic women. J Food Prot 2011, 74:949-953.

10. Linnan MJ, Mascola L, Lou XD, Goulet V, May S, Salminen C, Hird DW, Yonekura ML, Hayes P, Weaver R: Epidemic listeriosis associated with Mexican-style cheese. N Engl J Med 1988, 319:823-828.

11. MacDonald P, Whitwam R, Boggs J, MacCormack J, Anderson K, Reardon J, Saah J, Graves L, Hunter S, Sobel J: Outbreak of listeriosis among Mexican immigrants as a result of consumption of illicitly produced Mexican-style cheese. Clin Infect Dis 2005, 40:677-682.

12. Thompson TL, Marth EH: Changes in Parmesan cheese during ripening: Microflora - coliforms, enterococci, anaerobes, propionibacteria and staphylococci. Milchwissenschaft Milk Science International 1986, 41:201-204.

13. Ordonez JA, Barneto R, Ramos M: Studies on Manchego cheese ripened in olive oil. Milchwissenschaft Milk Science International 1978, 33:609-612.

14. Terzic-Vidojevic A, Vukasinovic M, Veljovic K, Ostojic M, Topisirovic L: Characterization of microflora in homemade semi-hard white Zlatar cheese. Int J Food Microbiol 2007, 114:36-42.

15. Litopoulou-Tzanetaki $E$ : Changes in Numbers and Kinds of Lactic Acid Bacteria During Ripening of Kefalotyri Cheese. J Food Sci 1990, 55:111-113

16. Centeno J, Menendez S, Rodriguez-Otero J: Main microbial flora present as natural starters in Cebreiro raw cow's-milk cheese (Northwest Spain). Int J Food Microbiol 1996, 33:307-313.

17. Berthier F, Beuvier E, Dasen A, Grappin R: Origin and diversity of mesophilic lactobacilli in Comte cheese, as revealed by PCR with repetitive and species-specific primers. Int Dairy J 2001, 11:293-305.

18. Trovatelli LD, Schiesser A: Identification and significance of enterococci in hard cheese made from raw cow and sheep milk. Milchwissenschaft Milk Science International 1987, 42:717-719.

19. Beresford TP, Fitzsimons NA, Brennan NL, Cogan TM: Recent advances in cheese microbiology. Int Dairy J 2001, 11:259-274.

20. Quigley L, O'Sullivan O, Beresford TP, Ross RP, Fitzgerald GF, Cotter PD: Molecular approaches to analyzing the microbial composition of raw milk and raw milk cheese. Int J Food Microbiol 2011, 150:81-94.

21. O'Sullivan DJ: Methods for analysis of the intestinal microflora. Curr Issues Intest Microbiol 2000, 1:39-50.

22. Redford AJ, Bowers RM, Knight R, Linhart Y, Fierer N: The ecology of the phyllosphere: geographic and phylogenetic variability in the distribution of bacteria on tree leaves. Environ Microbiol 2010, 12:2885-2893.

23. Telias A, White JR, Pahl DM, Ottesen AR, Walsh CS: Bacterial community diversity and variation in spray water sources and the tomato fruit surface. BMC Microbiol 2011, 11:81.

24. Lewis T, Loman NJ, Bingle L, Jumaa P, Weinstock GM, Mortiboy D, Pallen MJ: High-throughput whole-genome sequencing to dissect the epidemiology of Acinetobacter baumannii isolates from a hospital outbreak. J Hosp Infect 2010, 75:37-41.

25. Quigley LF, O'Sullivan OF, Beresford TP, Ross RP, Fitzgerald G, Fitzgerald GF, Cotter P, Cotter PD: High-throughput sequencing for detection of subpopulations of bacteria not previously associated with artisanal cheeses. Appl Environ Microbiol 2012, 78:5717-5723.

26. Alegria A, Szczesny P, Mayo BF, Bardowski JF, Kowalczyk M, Kinde HF, Mikolon AF, Rodriguez-Lainz AF, Adams CF, Walker RL FAU, Cernek-Hoskins S, et al: Biodiversity in Oscypek, a traditional Polish cheese, determined by culture-dependent and -independent approaches. Appl Environ Microbiol 2012, 78:1890-1898.

27. Masoud WF, Vogensen FK, Lillevang S, Abu Al-Soud W, Sorensen SJ, Jakobsen M: The fate of indigenous microbiota, starter cultures, Escherichia coli, Listeria innocua and Staphylococcus aureus in Danish 
raw milk and cheeses determined by pyrosequencing and quantitative real time (qRT)-PCR. Int J Food Microbiol 2012, 153:192-202.

28. White JR, Nagarajan N, Pop M: Statistical methods for detecting differentially abundant features in clinical metagenomic samples. PLOS Comput Biol 2009, 5:e1000352.

29. Renye J Jr, Somkuti G, Vallejo Cordoba B, Van Hekken D, Gonzalez-Cordova A: Characterization of the microflora isolated from queso fresco made from raw and pasteurized milk. Journal of Food Safety 2008, 28:59-75.

30. Saubusse MF, Millet LF, Delbes CF, Callon CF, Montel MC: Application of Single Strand Conformation Polymorphism -PCR method for distinguishing cheese bacterial communities that inhibit Listeria monocytogenes. Int J Food Microbiol 2007, 116:126-135.

31. Callon CF, Duthoit FF, Delbes CF, Ferrand MF, Le Frileux YF, De Cremoux RF, Montel MC: Stability of microbial communities in goat milk during a lactation year: molecular approaches. Syst App/ Microbiol 2007, 30:547-560.

32. Liu F, Wang D, Du L, Zhu Y, Xu W: Diversity of the Predominant Spoilage Bacteria in Water-Boiled Salted Duck during Storage. J Food Sci 2010, 75:M317-M321.

33. Collins MD, Lund BM, Farrow JA, Schleifer KH: Chemotaxonomic Study of an Alkalophilic Bacterium, Exiguobacterium aurantiacum gen. nov., sp. nov. J Gen Microbiol 1983, 129:2037-2042.

34. Fruhling A, Schumann P, Hippe H, Straubler B, Stackebrandt E: Exiguobacterium undae sp. nov. and Exiguobacterium antarcticum sp. nov. Int I Syst Evol Microbiol 2002, 52:1171-1176.

35. Chocolatewala N, Chaturvedi P, Desale R: The role of bacteria in oral cancer. Indian J Med Paediatr Oncol 2010, 31:126-131.

36. Rodrigues DF, Tiedje JM: Multi-locus real-time PCR for quantitation of bacteria in the environment reveals Exiguobacterium to be prevalent in permafrost. FEMS Microbiol Ecol 2007, 59:489-499.

37. Vishnivetskaya TA, Petrova MA, Urbance J, Ponder M, Moyer CL, Gilichinsky DA, Tiedje JM: Bacterial community in ancient Siberian permafrost as characterized by culture and culture-independent methods. Astrobiology 2006, 6:400-414

38. Siddikee MA, Chauhan PS, Anandham R, Han GH, Sa T: Isolation, characterization, and use for plant growth promotion under salt stress, of ACC deaminase-producing halotolerant bacteria derived from coastal soil. J Microbiol Biotechnol 2010, 20:1577-1584.

39. Borsodi A, Kiss R, Cech G, Vajna B, Toth E, Marialigeti K: Diversity and activity of cultivable aerobic planktonic bacteria of a saline Lake located in Sovata, Romania. Folia Microbiol 2010, 55:461-466.

40. Okeke B: Bioremoval of hexavalent chromium from water by a salt tolerant bacterium, Exiguobacterium sp. GS1. Journal of Industrial Microbiology \& Biotechnology 2008, 35:1571-1579.

41. Jameson JE: A discussion of the dynamics of salmonella enrichment. Journal of Hygiene, Cambridge 1962, 60:193-207.

42. Mellefont LA, McMeekin TA, Ross T: Effect of relative inoculum concentration on Listeria monocytogenes growth in co-culture. Int J Food Microbiol 2008, 121:157-168.

43. Tran T, Stephenson P, Hitchins A: The effect of aerobic mesophilic microflora levels on the isolation of inoculated Listeria monocytogenese strain LM82 from selected foods. Journal of Food Safety 1990, 10:267-275.

44. Al-Zeyara SA, Jarvis B, Mackey BM: The inhibitory effect of natural microflora of food on growth of Listeria monocytogenes in enrichment broths. Int J Food Microbiol 2011, 145:98-105.

45. Nocker A, Richter-Heitmann T, Montijn R, Schuren F, Kort R: Discrimination between live and dead cells in bacterial communities from environmental water samples analyzed by 454 pyrosequencing. Int Microbiol 2010, 13(2):59-65.

46. Pan Y, Bodrossy L, Frenzel P, Hestnes AG, Krause S, Luke C, Meima-Franke M, Siljanen H, Svenning MM, Bodelier PL: Impacts of Inter- and Intralaboratory Variations on the Reproducibility of Microbial Community Analyses. Appl Environ Microbiol 2010, 76:7451-7458.

47. Angiuoli SV, Matalka M, Gussman A, Galens K, Vangala M, Riley DR, Arze C, White JR, White O, Fricke WF: CloVR: a virtual machine for automated and portable sequence analysis from the desktop using cloud computing. BMC Bioinforma 2011, 12:356.

48. Caporaso JG, Kuczynski J, Stombaugh J, Bittinger K, Bushman FD, Costello EK, Fierer N, Pena AG, Goodrich JK, Gordon Jl: QIIME allows analysis of high-throughput community sequencing data. Nat Methods 2010, 7:335-336.
49. Schloss PD, Westcott SL, Ryabin T, Hall JR, Hartmann M, Hollister EB, Lesniewski RA, Oakley BB, Parks DH, Robinson CJ: Introducing mothur: open-source, platform-independent, community-supported software for describing and comparing microbial communities. Appl Environ Microbio 2009, 75:7537-7541.

50. Edgar RC, Haas BJ, Clemente JC, Quince C, Knight R: UCHIME improves sensitivity and speed of chimera detection. Bioinformatics 2011, 27:2194-2200

51. Wang Q, Garrity GM, Tiedje JM, Cole JR: Naive Bayesian classifier for rapid assignment of rRNA sequences into the new bacterial taxonomy. Appl Environ Microbiol 2007, 73:5261-5267.

52. White JR, Arze C, Team TC, Matalka M, White O: CloVR-16S: Phylogenetic microbial community composition analysis based on 165 ribosomal RNA amplicon sequencing - standard operating procedure, version 1.1. http://precedings.nature.com/documents/5888/version/2.

doi:10.1186/1471-2180-12-254

Cite this article as: Lusk et al:: Characterization of microflora in Latinstyle cheeses by next-generation sequencing technology. BMC Microbiology 2012 12:254.

\section{Submit your next manuscript to BioMed Central and take full advantage of:}

- Convenient online submission

- Thorough peer review

- No space constraints or color figure charges

- Immediate publication on acceptance

- Inclusion in PubMed, CAS, Scopus and Google Scholar

- Research which is freely available for redistribution 